\title{
Swings and Roundabouts: The Impact of Legal Drafting on the Language and Understanding of Copyright Law and the Need for Educational Materials
}

\author{
Ms. Hayleigh Bosher* and Dr. Dinusha Mendis** \\ *PhD Candidate (Copyright), Centre for Intellectual Property Policy and Management (CIPPM), \\ Bournemouth University (hbosher@bournemouth.ac.uk); \\ ${ }^{* *}$ Associate Professor in Law and Co-Director of the Centre for Intellectual Property, Policy and \\ Management (CIPPM), Bournemouth University (dmendis@bournemouth.ac.uk). \\ The authors form part of the Copyrightuser.org team and are the authors of the educational resources \\ published in the 'education and schools' section on Copyrightuser.org. Copyrightuser.org is a \\ collaborative project between CIPPM, Bournemouth University and CREATe, University of Glasgow.
}

\begin{abstract}
Legislators face the challenging task of drafting copyright law, which takes into account the views of various stakeholders, intended policy and technological developments whilst ensuring that the wording and language that is used is accurate and precise. Meeting these objectives means that the law in its legislative form can be hard-to-understand, complex and not easily accessible to the layperson. This article explores steps, which have been put in place by various organisations and online resources to assist in the understanding of copyright for the public and schools, with particular focus on education and teaching materials - as presented on Copyrightuser.org.
\end{abstract}

Keywords: Copyright, Legislation, Legal Drafting, Legal Education, Language

\section{Introduction}

The question of 'is this a bill that current stakeholders agree on' is not the same as asking 'is this a good bill' (Litman 2006).

The underlying meaning of the above quote highlights the laborious task faced by the legislator ${ }^{1}$ in drafting "a good bill", whilst unpacking the above statement reveals a three-fold challenge for the drafter. This includes (a) reflecting the views of the various stakeholders in a given political and economic environment within which the law will be practised (Dworkin and Taylor 1989) whilst (b) drafting a bill that is accurate and one which (c) responds to intended policy including developments in society, such as technology (Feather 1994). Striking this delicate balance is a complex task involving compromise (Arnold 2015) and similar to other areas of law this is also true in the context of copyright law. 


\section{A final version of this paper will appear in Issue 3 [2016] International Review of Law, Computers and Technology}

At the same time, it is important to understand that "identifying the goal of the drafter as 'achieving quality in legislation' is a rather short-sighted and narrowly-focused approach" (Xanthaki 2014). This is because the "drafter can only aim to perform well in their little, albeit crucial, part in the application of governmental policy, better expressed as regulation" (Xanthaki 2014). Xanthaki (2014) argues that it is more accurate to identify the goal of the drafter as "pursuing quality in regulation" (emphasis added).

Xanthaki (2014) further elaborates this point through a 'pyramid-style diagram' consisting of four levels, which in turn reflects the goals of the drafter. These include (a) efficacy (at the tip of the pyramid); (b) effectiveness; (c) efficiency, clarity and precision; and (d) simplicity and plain language (at the very bottom of the pyramid).

An appreciation of Xanthaki's argument, with particular focus on (d) above, helps understand why legislation is often considered to be complex by the layman. Meeting these various objectives, in the order of their hierarchy, means that whilst the law may be fit-for-purpose in terms of efficacy (for example, reflecting stakeholder views and intended policy); effectiveness; efficiency, clarity and precision, the law in its legislative form can also be hardto-understand and complex for the layman.

It is clear that whilst the legislator pays close attention to the language and wording of the bill, simplicity and plain language is not their priority. It is more important for the drafter to select the most appropriate word or words for the bill. For example if the words are too specific the law may become quickly redundant in the face of technological developments (Feather 1994). On the other hand, technologically broad terminology may result in unintended meanings in the law. This is further reflected by the fact that the legislator is often restricted by specific legal drafting techniques, such as being restricted from using certain words in the text. ${ }^{2}$

Sir George Engle states that "complication arises from Parliament's desire for detail, from the intricate subject matter, from the previous body of law, and from our passion for fairness" (Neville Brown 1988). Yet, these are the very ingredients, which are needed to produce a "good bill" which is ultimately fit-for-purpose.

At the same time, for the law to retain its value and importance it is essential that the law is accessible to the layman. In other words, at the very least, people should be aware of the law, when they behave unlawfully (Hargreaves 2011). This point is emphasised by current literature, which suggests that an increase in knowledge of copyright law could also increase the lawful use of copyright materials (Hargreaves 2011). To address this issue there have 


\section{A final version of this paper will appear in Issue 3 [2016] International Review of Law, Computers and Technology}

been attempts by organisations and online resources to create copyright educational resources adopting a grassroots approach. The aim of these resources is to make copyright law accessible to the layperson as well as students and teachers. The importance of making the law accessible at grassroots level is further emphasised by research, which suggests that copyright understanding is particularly important in younger people (Kantar Media 2015).

This paper explores the challenges of drafting copyright legislation and highlights its implications on the language of the law. As copyright law regulates the use of creative content, it is necessary for the public to have at least a basic understanding of the concept of copyright in order that it might be effective. Therefore, the authors argue that there is a need for educational resources in order to make the law accessible to the layperson, students and teachers.

The various strands associated with legal drafting and accessible law is explored in three parts, in this paper. Part I identifies and discusses the challenges for the drafter in striking the balance between reflecting stakeholder views on the one hand (i.e. meeting the objectives of efficacy and effectiveness), whilst drafting a bill that is clear and accurate in terms of terminology in responding to the intended meaning of the policy.

Part II of this paper argues that in meeting these various objectives within a complex environment of multi-stakeholder interests, leads to complicated law that is inaccessible to the general public. Therefore, Part II explores the public understanding of copyright and outlines some educational initiatives that have attempted to address this issue by providing resources to the public and schools.

In doing so, Part III of this paper, refers to Copyrightuser.org - an online resource which aims to make copyright law accessible to creators, media professionals, entrepreneurs, teachers, students and members of the public. In this part of the paper, the authors draw on their experience of drafting an A Level Resource for Copyrightuser.org and provide a case study example of implementing copyright law within the A Level curriculum in England and Wales. As such, Part III aims to highlight the importance of providing accessible copyright materials as a complement to the legislation.

The paper concludes that drafting copyright law is a complicated process. The impact of the copyright environment and legislative drafting often results in complex law that is not accessible to the public. Therefore, there is a need for supplementary documentation to inform the public about copyright law. Moreover, research suggests that the need for 
copyright understanding is particularly significant for younger people and therefore copyright education in schools and colleges is required. This argument is further backed up by the Weatherley Report (2014), which concluded that "high quality educational materials are needed but not enough exist, or are well known about". Weatherley (2014) goes on to note that "teachers need help so that they have the confidence to deliver IP classes." However, as demonstrated by the analysis of the A Level Media Studies Educational Resource, this is not a straight forward process. There is a need to be balanced, independent and authentic in the content of the teaching materials as well as being able to engage the student's attention and understanding.

\section{Part I: The Challenges of Drafting Copyright Legislation \\ The Challenge of Incorporating Stakeholder Perspectives in Drafting Laws as a Direct Response to Policy and Emerging Technologies}

In legal drafting, there is a lean towards a need to achieve efficacy, effectiveness, efficiency and precision as explained by Xanthaki (2014). Meeting these objectives is a complex task. This section considers the challenges of drafting copyright law that intends to meet and balance the stakeholder interests whilst drafting law that is technologically accurate in responding to intended policy. It is interesting to note the paradoxical challenge for the drafter in the copyright law context. Often, stakeholders lobby for change due to technological developments, which have an impact on the protection and exploitation of creative works whilst the drafter has to ensure that in responding to the policy and technology, the law is not technologically specific, leading to it becoming redundant in the face of new technologies. Through this discussion, the following section highlights the challenges for the drafter and leads on to a discussion of its implications for the language of the law.

Copyright legislation has a history of being criticised for its complexity, whilst drafting of copyright legislation appears to be particularly challenging for the following reasons.

The first challenge is that the legislation reflects the debates and compromises made between the different stakeholders at the time of drafting (Dworkin and Taylor 1989). For example, when the photocopier was developed, it was considered a serious threat to copyright holders; owing to making the copying of books quicker and cheaper (Feather 1994). 


\section{A final version of this paper will appear in Issue 3 [2016] International Review of Law, Computers and Technology}

Subsequently, the Gregory Committee was set up to consider desirable changes in the law relating to copyright with particular regard to technical developments (Gregory Committee 1952). In particular, the Committee was confronted with various conflicts of interest relating to the technological developments in photocopying (Gregory Committee 1952). For example, the publishers objected to a law which would allow large-scale copying; scholars wanted to be able to make copies for their own use; and librarians needed a clear law which would give them unequivocal guidelines (Gregory Committee 1952).

In order to address these conflicting interests the Gregory Committee of 1952 suggested an extension of fair dealing so that the law could allow reproduction by mechanical or photographic means of extracts, up to a certain length for private study. Feather (1994) described this balancing act as an "important conceptual innovation...an ingenious compromise."

The process of reaching such a consensus between the stakeholders was evidently challenging; demonstrated by the lengthy and complicated consultation process (Merkin 1989). The Copyright bill was finally brought to the House of Commons in the spring of 1988 after a great deal of research and consultation (HL Debate 12 November 1987) between lawyers, civil servants, publishers, authors, librarians, broadcasters, designers, industrialists and many others (Feather 1994). At the introduction of the second reading of the bill, the Chancellor of the Duchy of Lancaster and Minister of Trade and Industry, Mr. Kenneth Clarke acknowledged: "This bill comes here from another place... is lengthy and complex. It has 285 clauses and eight schedules." (HL Debate 28 April 1988).

It appeared that no amount of consultation and deliberation could avoid the multiple difficulties in reforming copyright law (Groves 1991; Davies 2002). In fact, it appeared, that the more consultation that took place, the more irreconcilable viewpoints became apparent (Groves 1991; Davies 2002). As a result of such negotiation, the law became very long and specific (Litman 2006).

Litman (2006) criticised the development of copyright law in this way; that required stakeholder support: "No effected party is going to agree to support a bill that leaves it worse off than it is under [previous] law." Describing the Whitford consultation (1977), Leopold (1977) stated that copyright is unable to throw off the shackles of history.

Thus, the need to achieve agreement between stakeholders imposed constraints on the legislation (Litman 2006). For example, Cornish (1999) described the debate as "a ferment 


\section{A final version of this paper will appear in Issue 3 [2016] International Review of Law, Computers and Technology}

of proposition and counter-proposition." Drafting legislation in this way can cause distortion of the regulation.

The second challenge for the legislator lies in the unintended consequence of drafting technologically specific legislation in that such legislation can become outdated and inflexible. In other words, the second challenge lies in achieving accuracy and precision in the subsequent legislation (Xanthaki 2014). As Feather (1994) goes on to explain; the result of the ingenious compromise was that "the Gregory Committee left the United Kingdom with a very specific law which was applicable to the technological, economic and political situation of $1956 . "$

This was recognised by the Whitford Committee in the subsequent 1977 copyright consultation and the 1956 law was considered "inadequate to cope with photocopying and recording machines." Therefore, in drafting of the current copyright law, Copyright, Designs and Patents Act 1988 (hereinafter CDPA 1988), the Whitford Committee (1977) considered the previous 1956 Copyright Act to be very complicated and subsequently recommended that the new law be simplified.

The Whitford Report emphasised that the balance needed readdressing in the light of new technological development. The Whitford Committee Report (1977) states that "there is an almost universal desire to find a modus vivendi between, on the one hand, the legitimate copyright interests of authors and publishers to control or at least receive remuneration in respect of reproduction of their works and, on the other hand, the equally legitimate interest of those engaged in research, in servicing research and education who are mainly interested in the dissemination of information."

Nevertheless, the CDPA 1988 was considered, at the time, to be an improvement in terms of logic and clarity (Davis 2009); "the great consolidated law which some have been seeking for over a century" (Feather 1994).

However, doubts and hesitations on its meaning arose quickly (Lester and Mitchell 1989). As mentioned, technologically specific law is quickly made redundant in the face of technological developments. As a result the CDPA 1988 has been amended more than 80 times to keep up with emerging technologies and changing times (Arnold 2015). Consequently, the simplicity and clarity has been lost and the law is once again considered to be over-complicated (Arnold 2015).

What is clear from the above section is that drafting laws to reflect the views of competing stakeholders interests whilst responding to policy and emerging technologies can be 


\section{A final version of this paper will appear in Issue 3 [2016] International Review of Law, Computers and Technology}

challenging. Drawing a line through history demonstrates the reactive nature of copyright law to technology. It is also for this reason, that the legislators face the challenging task of drafting law that is technologically accurate, yet, not technologically specific. As discussed above, doing so has many drawbacks including the law becoming redundant as technology marches on. Ensuring that the legislator meets all these objectives has a clear impact on the language of the law, which is discussed in the section below.

\section{The Impact of Compromise in Legal Drafting on the Language of the Law}

As discussed above, the legislative process involves taking into account various stakeholder perspectives whilst ensuring that the law that is created is technologically accurate. Striking this balance can be challenging and has a direct impact on the language of the law. In particular, meeting these objectives means that whilst the law may be 'fit for purpose', the wording of the law may appear to be archaic and obscure to a layperson. ${ }^{3}$

This is a characteristic of legal drafting. Legal language is difficult to understand for those who are not legally trained, largely due to the syntax characteristics (Cucchi 2010). For example, the meaning of words may be different in another context, outside of the law (Garzone 2010). In addition, whereas ordinary prose has nominalisation, mood and tense, legal language does not; making it appear incoherent to those who are not specialised in the law (Wanger and Cacciaguidi-Fahy 2006).

For these reasons the law may be criticised for being inaccessible to the public. However, due to the process of writing legislation and the need to be specific in law, it is not plausible to create regulation using the every-day interpretation of language as this would lead to ambiguity in the meaning of the law (McAuliffe 2013).

Ambiguity in the law causes uncertainty, which leaves stakeholders and the public vulnerable to unstable positions. To avoid this, drafters are restricted in their use of certain words or phrases. For example, drafters are now refrained from using the word "shall" due to the ambiguity of the word meaning both a passive and obligatory term (Williams 2006).

Furthermore, the structure of our legal system also plays a role in the formation of legal documents. In particular, any laws that are transposed from European law, for example European Directives ${ }^{4}$, are subject to language restraints in the process of the law being translated in to 24 different languages (McAuliffe 2014). 


\section{A final version of this paper will appear in Issue 3 [2016] International Review of Law, Computers and Technology}

As mentioned, copyright law is often re-drafted as a response to developing technologies. ${ }^{5}$ In doing so, 'technical reviews' are adopted as part of the consultation process, which includes a discussion on the specific choice of terminology used to define the intended meaning. For example, in introducing the text and data mining exception under Section $29 \mathrm{~A}$ and Schedule 2(2)1D CDPA 1988, the Government Response (2014) queried if the term "electronic analysis" reflected the range of analytical techniques used in research. Whilst some stakeholders felt that the term was appropriate to describe the range of activities normally meant by text and data mining, others argued that a more detailed definition was needed (Government Response 2014). Another response argued that the term was too technologically specific and suggested "computational" as an alternative (Government Response 2014).

The Government Response (2014) stated its intention to draft legislation that is technologically neutral and, in this instance, to permit all activities that could reasonably be considered to be "text and data mining". Therefore, the draft legislation was updated and the wording of the exception can be seen to reflect this discussion. For example, the word 'electronic' has been replaced by computational: "The copy is made in order that a person who has lawful access to the work may carry out a computational analysis of anything recorded in the work for the sole purpose of research for a non-commercial purpose" (Government Response 2014 emphasis added).

These examples demonstrate the challenges faced with drafting copyright legislation, which include the need to reach a compromise between the stakeholders, avoid being technically specific and yet carefully select wording that reflects the intended meaning of the law. The outcome of such influences on the drafting of copyright regulation is that the law can appear complex and therefore inaccessible to the general public.

However, it is necessary for the law to be accessible to those who are subject to the law (Litman 2006). According to the most recent survey by Kantar Media (2015), awareness and understanding of copyright infringement remains confusing for users. The study found that $40 \%$ of Internet users claimed to be either "not particularly confident" or "not at all confident" in terms of what is and is not legal online" (Kantar Media 2015).

The complexity of copyright law in relation to online copyright means that knowledge cannot be taken for granted. For example, the Palfrey, Gasser, Simun and Barns study (2009) revealed that when students were asked "do you know what copyright means?" $84 \%$ 


\section{A final version of this paper will appear in Issue 3 [2016] International Review of Law, Computers and Technology}

responded yes. However, their subsequent description of copyright was either wholly or partially incorrect (Palfrey et al. 2009).

In order to cooperate with the law, individuals need to be aware that the law exists (Henshel 1978). Thus there is a demand for copyright materials that are accessible to the public, explaining the law in simple terms (Weatherley 2014).

\section{Part I: Conclusion}

Part I of this paper outlined and discussed the reasons why copyright legislation is considered complex with particular emphasis on legal drafting. The authors identified two challenges in the present context. These include drafting law to incorporate stakeholder perspectives whilst responding to policy and emerging technologies. As discussed above, in effect, these two challenges can be seen as paradoxical in a copyright context. Quite often, stakeholders lobby for change due to technological developments, which have an impact on the protection and exploitation of copyright works whilst the drafter has to ensure that in responding to policy and technology, the law is not technologically specific, leading to it becoming redundant in the face of new technologies. Taking these challenges into account, the difficult task faced by the legislators has to be appreciated.

At the same time, it is important that the law is accessible to the non-lawyer, which may not always be possible due to the factors and challenges discussed above. As a result there is a clear demand for more helpful copyright information to supplement the regulation (Weatherley 2014). Therefore, whilst it may not be conceivable to draft laws that are accessible to the lay person, as reasoned above, it is necessary to communicate copyright regulation to the public.

In recognising this, Part II of this paper sets out the various means by which the law has been transposed into accessible materials thereby raising awareness to educate the public as well as students and teachers in copyright law. Whilst recognising the complexities of the legislation and the need for the law to be drafted in the manner it is done, the resources discussed below highlight the importance of providing supplementary materials in an accessible language that retains the essence of the law.

\section{Part II - Understanding Copyright Law: Resources for the Public and Schools}




\section{A final version of this paper will appear in Issue 3 [2016] International Review of Law, Computers and Technology}

The need for copyright material that is accessible to the public and schools has been recognised by organisations and resources such as The Copyright Hub, The UK Intellectual Property Office (UKIPO) and Copyrightuser.org.

To meet this objective, these organisations and resources have produced copyright materials relevant for the general public as well as for teachers and students. This section details the various initiatives by demonstrating the manner in which these copyright resources have been produced and targeted to suit the public as well as teachers and students. Some initiatives, such as the UKIPO and Copyrightuser.org, cater for the public as well as teachers and students.

\section{Resources for the Public: Making Copyright Law Accessible}

There are at least two recent major efforts towards creating resources for the general public that focus on education and understanding of copyright law.

The first is the Copyright Hub which was established following the recommendations made in the report by Richard Hooper and Dr Ros Lynch in 2012. According to the Copyright Hub website, the hub aims to provide basic, general information about copyright as one of their five main ambitions to become "the place to go for copyright education" (Hooper and Lynch 2012). However, the main focus of The Hub is to be a network for organisations and a market place for licensing (Creative Industries 2013).

To assist the general public understanding the new reforms, which were introduced in October 2014 (Baroness Neville-Rolfe 2014), the UKIPO published eight resources on the meaning of the new copyright exceptions on its website. These targeted guides aim to explain what users can and cannot do with copyright material. They explain what the changes mean for different groups of people including teachers, researchers, librarians, disability groups, artists, museums and consumers (Viscount Younger of Leckie 2014). These initiatives acknowledge the need for publicly accessible materials that explain the law.

It should also be noted that copyright industry stakeholders have invested a large sum of money in copyright awareness campaigns ${ }^{6}$ even though, these campaigns have sometimes come under criticism for being ineffective (Hargreaves 2011). For example, both the British Music Rights (now UK Music) and Childnet have created lesson plans in an attempt to introduce copyright into school education, thereby encouraging the adoption of a grass-roots approach. EMI Music have stated: "We would like to see schools teaching copyright 


\section{A final version of this paper will appear in Issue 3 [2016] International Review of Law, Computers and Technology}

awareness so that pupils understand its importance not only to those contemplating music as a career, but to society generally" (Curtis 2004).

The following section moves on to discuss copyright educational materials and outlines various teaching resources, which aim to make UK copyright law accessible to teachers and students. Due to the nature of copyright, producing accessible educational and teaching resources is not a straightforward task. As mentioned, copyright law is very complicated and there are many diverse stakeholder perspectives to balance.

First, this section explores why there is a need for copyright education in schools before embarking on reviewing various education resources created by organisations and online resources. Thereafter, this section considers more closely the methodology used to construct an educational resource for A Level Media students; Contemporary Media Regulation: A Case Study in Copyright Law. More specifically, it considers the challenges that arise in attempting to address copyright education and how these were overcome by this particular project.

\section{Teaching Resources for Schools: Adopting a Grass-Roots Approach}

This paper has already recognised the need for educational materials that make copyright law accessible to the general public. However, in creating such resources it is necessary to consider the target audience. This paper argues that the most effective approach in attempting to educate the public about copyright law is to adopt a grass-roots approach.

This argument is supported by a number of Research Studies that indicate a need to focus education towards the younger generations; moving from the grassroots up (Watson Zizzo and Fleming 2014). The underlining finding is that younger people are more likely to use digital copyright material illegally (Watson 2014). An example of this issue can be reflected through the Authors Licensing and Copyright Society (ALCS) and the National Schools Partnership, which hold an Annual Competition and Education Programme published on their website as "The Young Writer's Guide to Shakespeare." The competition aims to inform young people about copyright.

As part of the competition ALCS also monitors the student's attitudes, before and after the programme, and publishes the results on their website. In 2014 the results showed that $76 \%$ of students believed copyright should be taught in schools, there was a $19 \%$ increase in the 


\section{A final version of this paper will appear in Issue 3 [2016] International Review of Law, Computers and Technology}

number of students who understood that copyright applies to digital media and $56 \%$ showed preference to pay for content rather than illegally download. However, the results also showed that students who completed the programme were still uncertain about which websites were lawful. This suggests that more needs to be done.

More recently, the 2015 Kantar Media study found that since 2013, there has been no significant change in the level of confidence in knowing what is lawful or unlawful online.

Whilst the research and empirical studies points in the direction of the need for a grass-roots approach, the school education system in the UK does not formally provide for intellectual property or copyright education. ${ }^{7}$ For example, the Weatherley Report (2014) concluded that "high quality educational materials are needed but not enough exist, or are well known about." He also goes on to note that "teachers need help so that they have the confidence to deliver IP classes" (Weatherley 2014).

Recognising and responding to this gap, the UKIPO have produced material for teachers and students. ${ }^{8}$ Recently in 2015, and together with the Office of Harmonisation in the Internal Market (OHIM), the UKIPO has launched a website: Cracking Ideas. This website is a hub for intellectual property (IP) education materials from the UKIPO providing teachers with free resources, advice and guidance on Intellectual Property. Cracking Ideas does this through initiatives such as Nancy and the Meerkats; a radio series that can be downloaded from the website. In the radio series, which is aimed at the under 12s, Nancy and her backing band the Meerkats, are trying to make it big in the music industry and have to overcome a range of IP issues.

Cracking Ideas also provide clearly structured curriculum-linked lesson plans and activities for students' aged 4 to 16, plus higher education. In particular they provide a range of resources starring much-loved inventors Wallace and Gromit. This includes lesson plans suitable for 4-7 and 8-11 year olds that explore different aspects of creativity.

Cracking Ideas provides a vast and comprehensive range of educational materials for teachers, engaging in all age ranges and many subject areas. The focus of the materials is on creativity and innovation. For example the Lesson Plan for 12-16 year olds aims to engage students with the challenges and opportunities of product design. Another example is Creating Movie Magic, activates aimed at 11-14 year olds intended to open up a debate about the value of IP thereby encouraging the student's own creative talents. 


\section{A final version of this paper will appear in Issue 3 [2016] International Review of Law, Computers and Technology}

More recently, on the $10^{\text {th }}$ February 2016 , the UKIPO announced the launch of a new and updated ThinkKit that aims to help students understand the importance of protecting and respecting IP law. ThinkKit is a resource pack that includes lessons plans for teachers of GCSE or NQ Business Studies, Media Studies, Design Technology or Music, which enable them to encourage their students to think about innovation and protect their ideas. Baroness Neville-Rolfe, Minister for intellectual property, said: "It is essential that we educate children about the importance of intellectual property rights. From today these practical, real-world lesson plans will support the UK curriculum" (Baroness Neville-Rolfe 2016).

A second well-established resource is Copyrightuser.org an independent resource launched in 2014. Copyrightuser.org is an online resource aimed at making UK copyright law accessible to creators, media professionals, entrepreneurs, teachers and students, and members of the public.

Copyrightuser.org differs significantly from other resources due to its methodology, independence and focus. Its methodology involves taking a 'bottom-up' approach to provide answers to the most pressing concerns about copyright. Along with providing a 'FAQ' section on copyright ${ }^{9}$ the resource also includes videos ${ }^{10}$ and textual material written by Copyright experts in the UK in order to address the most pressing issues faced by creators.

Secondly, a further benefit of this resource is that it is independent as opposed to the previous examples, which are associated with or supported by copyright stakeholders.

Thirdly, and in addition, Copyrightuser.org aims to bring copyright regulation directly into focus by creating resources that explain the law in an accurate yet accessible manner. This differs from the UKIPO's Cracking Ideas initiative, which encourages creativity and innovation into a range of subject areas.

Embodying these various elements, Copyrightuser.org has a specific educational section, which is aimed at teachers and students. The resource adopts an innovative approach by taking an in-depth look at the methodology of an A Level educational resource and adapting it into a copyright context. To meet this objective, Copyrightuser.org collaborated with Oxford, Cambridge and RSA (OCR) Exam Board to introduce the resource to Schools in England and Wales. Over and above producing the teaching materials, a main aim of Copyrightuser.org is to ensure its dissemination and use within Schools in England and Wales. To this end, the project is currently continuing its work in this area and will do so throughout 2015-2016. 


\section{Part II: Conclusion}

The above section considered the various initiatives adopted by organisations and online resources to create accessible copyright materials for the public and schools. From the Copyright Hub, to the initiatives of copyright stakeholders, to the UKIPO and Copyrightuser.org all these resources aim to provide an understanding of the law so that the public and students have an awareness of what is lawful and the implications of unlawful behaviour on copyright protected works.

The section was brought to a conclusion with a focus on Copyrightuser.org with the authors highlighting the different approach adopted by this resource. The third and final part of this paper will now make a detailed analysis of the copyrightuser.org A Level teaching resource as a case study example of introducing copyright law to schools in England and Wales.

\section{Part III: Copyright for A-Level Media Studies}

As mentioned above, as part of the Copyrightuser.org Schools and Education objective, a copyright educational resource was created for A Level Media Students titled Contemporary Media Regulation: A Case Study in Copyright Law. ${ }^{11}$ The present authors are the authors of the A Level educational resource (Bosher and Mendis 2015) and they will draw upon their experience of authoring the educational material for A Level Media students to provide for a case study in this part of the article. This section of the article therefore discusses the methodological approach undertaken by the authors in order to meet the challenges of teaching copyright law to A Level Media students. ${ }^{12}$

At the outset, it is important to point out that A-Level Media Studies students that are examined under the OCR Examination Board are free to study any case studies, debates and issues, providing that they relate to four set questions ${ }^{13}$ that are listed in the Unit Specification. Therefore, the authors adapted the four (media-related) questions to reflect case studies in copyright law. ${ }^{14}$

To achieve this aim, the four questions in the OCR Unit Specification were adapted into a questionnaire, which was sent out to a broad range of copyright stakeholders. This was particularly important as the title of the Media Studies Unit, within which the resource is used was "Critical Perspectives in Media: Contemporary Media Issues." The responses generated an interesting landscape of the various perspectives on copyright, including the views of individual creators, rights holders, EU and UK regulators, collecting societies, Internet 


\section{A final version of this paper will appear in Issue 3 [2016] International Review of Law, Computers and Technology}

Service Providers and users' representatives, amongst others. The responses received from the stakeholders were then analysed and used to construct the resource.

Using qualitative techniques, the responses to the questionnaire were coded into the most common copyright issues. The authors identified 18 common issues from the coding process. These included (1) originality, (2) new business models, (3) perceptions, (4) technology and (5) education, amongst others. This allowed the authors to systematically categorise the responses to illustrate the different stakeholder perspectives on the most current and pressing issues surrounding copyright regulation and media. This approach also enabled the authors to capture various copyright issues through practical examples thereby providing teachers and students with robust, raw material with which to debate contemporary media issues.

The resource is structured using the four 'prompt questions' that the students will address in their exam, with each prompt being broken down into three sub-questions; a case study and a task (Bosher and Mendis 2015). By providing consistency in structure and mirroring the exam, the resource supports the student's ability to learn the information and later recall the memory. This is because when committing information to memory, the more organised the information, the easier it is to recall (Weist 1972). As Willingham (2008) explains, "more important than the passage of time...is the quality of the cues you have to get to the memory."

\section{Producing Effective Copyright Teaching Materials: Learning Lessons from Cognitive Theory}

In producing the educational resource for A Level Media students, the authors adopted an approach, which encourages learning based on psychological concepts of understanding how new information is memorised, stored and recalled.

It is recognised that memory of new knowledge is fragile, but becomes more stable once the new knowledge is recorded in long-term memory stores (Hess and Friedland 1999). Consequently, to acquire new knowledge, humans need to attend to the new information and maintain it until it can be encoded from short-term (Baddeley and Hitch 1974) into longterm memory (Hess and Friedland 1999). 


\section{A final version of this paper will appear in Issue 3 [2016] International Review of Law, Computers and Technology}

Firstly, it is suggested that knowledge is much more likely to be encoded and recalled later if the new concepts can be linked together in a framework of existing knowledge. ${ }^{15}$ Many students are better able to make sense of new concepts and encode them only after they can see the "big picture" (Hess and Friedland 1999). In light of this, the authors grounded the legal regulation in context in order to make the resource most effective. The new concepts of law are integrated with real life scenarios that the students can relate to. The aim of this approach is to engage students with a mutual point of reference and build on their existing knowledge as a framework for introducing new legal concepts.

Schwartz (2001), in supporting this technique argues that legal texts should include authentic, real-world problems. He goes onto explain that the best legal textbooks "allow students to practice applying the concepts as they learn them...introduce topics with overviews and a problem the students can solve once they have learned the topic" (Schwartz 2001).

This is implemented in the resource (Bosher and Mendis 2015) at the end of every section by way of a case study to discuss the ideas that are presented within the section in a relevant context that students and teachers can relate to. For example, the case study under Prompt One, explores copyright as an incentive for reward by drawing on an example about J. K. Rowling. The example demonstrates how the copyright framework was utilised to support her financially and reward her for creating the Harry Potter stories. It then goes on to discuss how the stories and characters were licenced in order to create further works such as the films, video games and so on (Bosher and Mendis 2015). This case study allows the students to map the copyright knowledge they have learned onto a familiar context.

Secondly, research has shown that the meaningfulness of a stimulus has a substantial effect on its memorability and that deeper levels of analysis produce stronger memory traces than shallow levels of analysis (Craik and Lockhart 1972). Therefore, instead of focusing on the academic or theoretical areas of copyright, the authors took a practical approach focusing on the real world meaning of copyright. In particular, the content of the learning resource was directed by the data collected by copyright stakeholders' questionnaire responses. The stakeholder responses also offer real life examples to support the statements made within the text. For example, Prompt Two (Bosher and Mendis 2015) demonstrates the effectiveness of using stakeholder statements to support or criticise copyright regulation, as experienced in practice, which in turn make the arguments more compelling. The above point can be further elaborated with reference to a quote from one of the stakeholders who stated: "having copyright in my own work has allowed me to make a living from the 


\section{A final version of this paper will appear in Issue 3 [2016] International Review of Law, Computers and Technology}

photographs produced. Without copyright I would not have been able to support myself doing this work over the last 40 years creating a body of work which has been widely published." (Bosher and Mendis 2015)

Thirdly, it is understood that information is encoded into long-term memory by rehearsal (Rundus and Atkinson 1970). For this reason the basic concepts of copyright are repeated throughout the resource. Moreover, students are encouraged to recall and apply their knowledge on copyright law by way of task questions set out at the end of each section or 'Prompt'. For example, Prompt Three discusses the effectiveness of copyright regulation (Bosher and Mendis 2015). At the end of this section the students are set a task that requires them to apply the knowledge they have acquired to identify the application of copyright protection in different scenarios. Having read the opinions of others on the effectiveness of copyright regulation, the students are then asked to consider their own view.

Another important factor in assisting students to understand and memorise information is the nature and degree of precision of semantic elaborations, i.e., the way in which the words are presented (Bransford et al. 1979). Research has shown that information is recalled better when elaborated on (Craik and Tulving 1975), but most effective when the elaboration is minimal (Bransford et al. 1979). As a result, concepts in the resource are explained in accessible language, with efficient and mindful elaboration where needed.

Finally, it is understood that there are two different types of long-term memory, which can be defined as semantic and episodic (Tulving 1972). Semantic memory deals with specific events or experiences. ${ }^{16}$ For example, a student's previous experience with their use of copyright protected material could relate to listening to music at home. On the other hand, episodic memory deals with information relating to knowledge of the world, i.e., knowing that the music they are listening to was created by an artist and may be protected by copyright law.

Episodic and semantic memory involve different mental processes, but are intrinsically linked and depend heavily on each other and thus can influence the other. ${ }^{17}$ Therefore, it is important that in the resource, the authors constantly refer to real life examples. This is demonstrated in the resource by directly addressing the reader by including statements such as "if you are producing a video..." (Bosher and Mendis 2015). This is also reflected in the case study sections, which draw upon real life examples such as Harry Potter and Netflix in order to bring the 'law to life' through real-life scenarios and examples as highlighted above. 


\section{Communicating Copyright Law to Non-Law Students: A Resource for A Level Media}

\section{Students}

In producing effective copyright teaching materials, it is important to bear in mind that the students and teachers using the educational resource are not studying law. Research suggests that teaching law to non-law students requires a different approach (Johnstone 1996) which includes a deep consideration of the amount of legal content to include in the course (Owens and Wex 2014).

Owens and Wex (2014) found that non-law students struggled with the large quantity of material they were required to read and remember. Over and above this challenge, Owens and Wex (2014) also highlighted that the majority of students found the semantic density and subtlety of legal discourse problematic.

Moreover, it has been argued that the most effective learning materials are as short as possible, in order to retain student focus and attention (Muller 1995). Therefore, as mentioned above, the content of the resource was directed by copyright stakeholders responses and real-life scenarios. This allowed the authors to be concise in the chosen areas of copyright and bring the law life through real-life examples.

An additional concern for non-law students is that they often feel nervous when studying law; as they perceive it to be extremely difficult (Kariyawasam and Low 2014). The authors attempted to reconcile this with the use of accessible language and presenting the information in a user friendly way.

Furthermore, it is recognised that the use of appropriate imagery can assist in learning (Durwin and Sherman 2008). Therefore, the interface of the resource includes images, illustrations, visual diagrams and links to video content in order to encourage learning, which is one of the unique features of Copyrightuser.org as a whole.

It is understood that different students have different learning styles. ${ }^{18}$ Therefore, the resource does not restrict teachers to a specific lesson plan or classroom structure thereby enabling flexibility in teaching style, student interaction and learning environments.

When considering the content of an educational resource, it is important to encourage independence of thought, questioning, critical analysis and consideration of a range of alternatives without necessarily accepting one particular idea (Kariyawasam and Low 2014). The Government have expressed a commitment to creating an educational environment that stimulates critical thinking and creativity (Michael Gove 2014). By considering different perspectives on an issue (Willingham 2007) students learn to avoid biases, such as settling 


\section{A final version of this paper will appear in Issue 3 [2016] International Review of Law, Computers and Technology}

on the first conclusion that seems reasonable, or seeking evidence that confirms one's beliefs, or ignoring countervailing evidence (Willingham 2007).

Critical thinking needs to be taught in context of the subject. ${ }^{19}$ Therefore, the educational resource teaches copyright by drawing on the different perspectives of the people and organisations that have an interest in copyright (stakeholder responses). This approach reflects the nature of copyright as a balance of interests, as well as encouraging students to think critically about copyright.

The above section outlined the process, which was adopted to produce and author an educational resource on copyright law for A Level students studying Contemporary Media Regulation. The section also outlines concepts from cognitive theory for producing effective copyright teaching resources for non-law students whilst highlighting the lessons that can be learned. The next section outlines some of the limitations of the methodology and steps, which can be put in place for moving forward.

\section{Conclusion}

This article explored, in three parts, the impact of legal drafting on the language of copyright law and the subsequent need for supplementary materials to assist in the law being accessible to members of the public and schools. The article recognised that the law in its legislative form may not be coherent to the general public and concluded that both intricate legal documents as well as materials that are accessible to the public are required in areas of law such as copyright.

Part I of this paper, outlined the reasons why the law has to be drafted in the manner in which it is done. In particular, this section highlighted the challenges for the drafter, which was further illustrated by using Xanthaki's pyramid-style diagram as a point of reference. Striking the balance of reflecting the views of the various stakeholders whilst drafting a bill that is accurate and one, which responds to intended policy including developments in society, such as technology, is clearly a complex task. It also throws up a paradoxical challenge for the drafter in the copyright law context. Often, stakeholders lobby for change due to technological developments, which have an impact on the protection and exploitation of creative works whilst the drafter has to ensure that in responding to the policy and technology, the law is not too specific, leading to it becoming redundant in the face of new technologies.

Whilst meeting these objectives may ultimately lead to regulation, that is fit-for-purpose, it has an impact on the language of the law and may not be accessible to the layman, students 


\section{A final version of this paper will appear in Issue 3 [2016] International Review of Law, Computers and Technology}

and teachers. The 2014 Weatherley Report put this point into context by concluding that "high quality educational materials are needed but not enough exist, or are well known about" (Weatherley 2014).

Recognising this gap, Part II of this paper reasoned why there is a need for supplementary copyright resources for the public and schools and outlined the initiatives of various organisations and stakeholders to assist the public with an understanding of copyright law. In doing so, Part II established that adopting a grass-roots approach is the way forward - as also recognised by the UK Government on the Cracking Ideas website. As such, the paper drew a line through various initiatives, which have been set up to assist with making copyright law accessible to students with the aim of providing an awareness of what is lawful and the implications of unlawful behaviour on copyright protected works. The section highlighted Copyrightuser.org as one of the resources and distinguished it from the rest, in moving towards Part III.

Part III provided a case study example drawn from the 'Education and Schools' section of Copyrightuser.org. In particular, the section focused on the educational resource created for A Level Media Students, known as, Contemporary Media Regulation: A Case Study in Copyright Law. The section detailed the cognitive theory methodology, which was used to create this resource. In particular, the authors of the resource relied on the principles and concepts of cognitive theory in creating the resource for A Level Media students in England and Wales to ensure that the materials that were created were accessible for the intended audience - i.e., readers who are not legally trained, or necessarily interested in the detail of the law.

In drawing a conclusion and as demonstrated by the analysis of the A Level Media Studies Educational Resource, the importance of producing supplementary materials as a complement to the legislation is paramount, although it is not a straight forward process. It is important for any such resource to be balanced, independent and authentic in the content of the teaching materials as well as being able to engage the public's and student's attention and understanding. Copyrightuser.org aims to achieve this goal through the use of both textual and video materials and will assess the impact of the resource from 2016 onwards. To achieve this aim, the authors of the resource will work with OCR to track the number of students who opted to take the copyright case study as part of their A Level exam from 2016 onwards.

It is recognised by the UK Government (Weatherley 2014) as well as legal (Xanthaki 2014) commentators that Copyright Education Awareness is important, particularly at a grass-roots 


\section{A final version of this paper will appear in Issue 3 [2016] International Review of Law, Computers and Technology}

level. The hope for the future is that organisations and online resources such as Copyrightuser.org will take this initiative forward in making copyright law accessible to the public as well as schools.

\section{Notes}

${ }^{1}$ In a broad sense, law making and law reform is carried out by (1) Parliament; (2) Courts (in the interpretation of the law); and (3) Law Reform Agencies (LRA) such as the Law Commission of England and Wales (in an advisory role to the Parliament). For purposes of this paper, the authors refer to the Parliament in speaking of the legislator. In this context the term 'drafter' is used as an extension of this definition, taking into account the legal draftsmen who operate on behalf of the Government. See Zander, M. 2004. The Law Making Process. Cambridge: Cambridge University Press.

${ }^{2}$ For example drafters are now refrained from using the word "shall" due to the ambiguity of the word meaning both a passive and obligatory term. See, Christopher W., Fuzziness in Legal English: What Shall We Do with "Shall" in Wanger, A. and Cacciaguidi-Fahy, S. 2006. Legal Language and the Search for Clarity. Germany: Peter Lang, 237-263.

${ }^{4}$ To date there have been the nine copyright-specific Directives. These have included Directives on the protection of computer programs; rental/lending rights and related rights; satellite broadcasting and cable retransmission; term of protection; protection of databases; copyright in the information society; artist's resale right; orphan works and collective rights management, as well as the enforcement Directive, which is of wider application. The provisions of these copyright-related Directives have effect throughout the European Economic Area, comprising the European Union resulting in each Directive having to be translated into 24 languages leading to language restraints. Sterling, J. A. L., and Mendis, D. 2015. "Regional Conventions, Treaties and Agreements: Summary" in Cook, T. (ed) Sterling on World Copyright Law. London: Sweet \& Maxwell, Chapter 27.

${ }^{5}$ The drafting of the new text and data mining copyright exception introduced in 2014, is an example of this challenge. See, The Copyright and Rights in Performances (Research, Education, Libraries and Archives) Regulations 2014, No. 1372, regulation 3(2), amending section 29A CDPA 1988. See Lee, Y. H. 2015. "United Kingdom Copyright Decisions and Legislative Developments 2014" IIC 46(2): 226-237, 231-232.

${ }^{6}$ Copyright "stakeholders are therefore doing a huge amount of awareness raising to help people understand the value of IP in today's society." A repository of the copyright awareness campaigns throughout Europe can be found at: https://oami.europa.eu/ohimportal/en/web/observatory/public-awareness-campaigns

${ }^{7}$ The UK National Curriculum does not expressly provide for Intellectual Property education, however, it also does not prohibit it. See, Intellectual Property and Education In Europe. 2015. Study On IP Education in School Curricula in The EU Member States With Additional International Comparisons. Spain: Office for Harmonisation in the Internal Market, 34. See also, Weatherley, M. 2014. "Copyright Education and Awareness - A Discussion Document" available at: http://www.cubismlaw.com/wp-content/uploads/2015/06/mweatherly-copyrighteducation-awareness.pdf p. 21.

${ }^{8}$ As far back as 2006, the UKIPO published "Think Kit" a free educational resource aimed at 14 - 16 year olds to provide Intellectual Property learning within Enterprise Education: 
http://webarchive.nationalarchives.gov.uk/20140603093549/http:/www.ipo.gov.uk/whyuse/ed ucation/education-thinkkit.htm

${ }^{9}$ A study was conducted in order to discover the most frequently asked questions about copyright, using the same bottom up approach. The study sampled from the population using Yahoo Answers. This initial search provided 172,870 results. In order to limit the scope of the study, candidate cases were restricted to 'questions and answers written in English'. The sample was further limited by time period, using only those entries of one year old or less. This provided 24,438 results, ranging from May 2012 to April 2013. From these results, the first 200 were selected. The 200 results where categorised thematically in order to finally produce the top 20 most common questions. See http://copyrightuser.org/topics/faqs

${ }^{10}$ This can be illustrated by reference to the animated film on Copyrightuser.org, The Adventure of the Girl with the Light Blue Hair (Episode 1 of the 'Game is On! Web Series), which won an AHRC Research in Film Award for the 'Best Film in the Year' On 12 November 2015. In keeping with the methodology of Copyrightuser.org, 12 'Case Files' complement the video and draws on the various elements of the film to explore key principles and ideas underpinning copyright law, creativity, and the limits of lawful appropriation and reuse. The animated film was produced by Mr. Bartolomeo Meletti (CREATe, University of Glasgow) and Professor Ronan Deazley (Queens University of Belfast). The Case Files were authored by Ms. Hayleigh Bosher and Dr. Dinusha Mendis (CIPPM, Bournemouth University). The Case Files were edited by the General Editor of Copyrightuser.org, Professor Ronan Deazley.

${ }^{11}$ The project, which was carried out during 2013-2014 by researchers at the Centre for Intellectual Property Policy and Management (CIPPM) at Bournemouth University was funded by AHRC under a contract with CREATe, the RCUK Centre for Copyright and New Business Models in the Creative Economy at University of Glasgow.

${ }^{13}$ The questions in the Unit Specification are known as 'Prompts'. The Four Prompts are four bullet point sentences set out in the OCR Unit Guide, from which the students then have to develop answers relating to their chosen case study.

${ }^{14}$ The methodology used by the researchers to create the educational resource was approved by the OCR at their Annual AS/A Level OCR Media Studies Conference, which took place in London on 21 March 2014. See Bosher, H. and Mendis, D. 2015.

Contemporary Media Regulation: A Case Study in Copyright Law, 2 - 3.

${ }^{15}$ This is known as a schema. Schemas are mental structures that people use to organise their knowledge about the world. Schema theory was developed by Bartlett who argued that prior knowledge is stored in the brain in form of schemas, which provide one of the main ways in which information in memory is organised. See, Bartlett, F. C. 1932. Remembering: A Study in Experimental and Social Psychology. Cambridge: Cambridge University Press. This was developed by Rumelhart and Norman who suggested that schema learning occurs in three ways, including "accretion". This is where a new example of an existing schema is recorded and added to the relevant schematic information in long term memory. See, Rumelhart, D. E. and Norman, D. A. 1981. "Analogical Processes in Learning" in Anderson, J. R. (ed) Cognitive Skills and Their Acquisition. Hillsdale, NJ: Lawrence Erlbaum Associates Inc. 


\begin{abstract}
${ }^{16}$ Semantic memory is "a mental thesaurus, organised knowledge a person processes about words and other verbal symbols, their meaning and referents, about relations among them, and about rules, formulas and algorithms for the manipulation of these symbols, concepts and relations." Tulving, E. 1972. "Episodic and Semantic Memory" in Tulving, E. and Donaldson, W. (eds) Organisation of Memory. Hillsdale NJ: Lawrence Erlbaum Associates Inc; 1972.

${ }^{17}$ This is done through the tuning or restricting or memory schemas where they are either elaborated or refined through experiences indicating that the existing schema is not adequate in the former, or a new schema is created, often with reference to a similar, preexisting schema in the latter. See, Rumelhart, D. E. and Norman, D. A. 1981. "Analogical Processes in Learning" in Anderson, J. R. (ed) Cognitive Skills and Their Acquisition. Hillsdale, NJ: Lawrence Erlbaum Associates Inc.

18 "Learning style" refers to the characteristic way a person acquires and uses knowledge. "Theories about learning styles indicate that learners have a preferred mode of learning, that people learn in different ways, that a variety of learning styles will be present in any classroom, and that no one teaching method is effective for all students." Lustbader, P. 1999. "Seven Principles for Good Practice in Legal Education: Principle 7: Good Practice Respects Diverse Talents and Ways of Learning" J. Legal Educ. 49: 448 - 458, 455.

${ }^{19}$ Willingham goes on to explain for example that "knowing that a letter was written by a Confederate private to his wife in New Orleans just after the Battle of Vicksburg won't help the student interpret the letter unless he knows something of Civil War history." Willingham, D. T. 2007. "Critical Thinking, Why Is It So Hard to Teach?" American Educator: 8 - 19.
\end{abstract}

\title{
Reference List
}

Arnold, R. 2015. "The Need for a New Copyright Act: A Case Study in Law Reform." Queen Mary Journal of Intellectual Property 5(2): 110-131

Baddeley, A. D. and Hitch, G. J. 1974. "Working Memory" in Bower, G. H. (ed) The Psychology of Learning and Motivation. London: Academic Press

Baroness Neville-Rolfe and The Intellectual Property Office. 2016. Think Kit' lesson plans to improve the next generation's understanding of IP. available at:

https://www.gov.uk/government/news/minister-urges-uk-schools-to-promote-vital-ipeducation

Bartlett, F. C. 1932. Remembering: A Study in Experimental and Social Psychology. Cambridge: Cambridge University Press

Bosher, H. and Mendis, D. 2015. Contemporary Media Regulation: A Case Study in Copyright Law. available at http://copyrightuser.org/schools/a-level-media-studies/ 
Bransford, J. D. Franks, J. J. Morris, C. D. Stein, B. S. 1979. "Some General Constraints On Learning And Memory Research" in Cermak, L. S. and Craiks, F. I. M. (eds) Levels of Processing in Human Memory. Hillsdale, NJ: Lawrence Erlbaum Associates Inc.

Cornish, W. R. 1999. Intellectual Property: Patents, Copyright, Trade Marks and Allied Rights. London: Sweet and Maxwell

Craik, F. I. M. and Lockhart, R. S. 1972. "Levels of Processing: A Framework for Memory Research." Journal of Verbal Learning and Verbal Behaviour 11: 671 - 684

Craik, F. I. M. and Tulving, E. 1975. "Depth Of Processing and the Retention of Words in Episodic Memory." Journal of Experimental Psychology 104: 268 - 294

Creative Industries Report. 2013. Streamlining Copyright Licensing for the Digital Age, (The Copyright Licensing Steering Group) available at:

http://www.focalint.org/assets/files/2013 09 streamlining copyright for the digital age.pdf

Cucchi C. 2010. "Vague Expressions in the European Parliament: A Marker of Cultural Identity?" In Garzone, G. and Archibald, J. (eds) Discourse, Identities and Roles in Specialized Communication. Switzerland: Peter Lang

Curtis, P. 2004. Government Launches Schools Music Manifesto, available at: http://www.theguardian.com/education/2004/jul/06/schools.artsinschools

Davies, G. 2002. Copyright and the Public Interest. London: Sweet and Maxwell

Baroness Neville-Rolfe. 2014. Department for Business, Innovations and Skills, UKIPO, Major Reform of Intellectual Property Comes into Force, Press Release available at: https://www.gov.uk/government/news/major-reform-of-intellectual-property-comes-into-force

Durwin, C. C. and Sherman, W. M. 2008. "Does Choice of College Textbook Make a Difference in Students' Comprehension?" College Teaching 56: 28 - 34

Dworkin, G. and Taylor, R. D. 1989. Blackstone's Guide to the Copyright, Designs and Patents Act 1988. London: Blackstone Press Ltd

Dworkin, G. 1977. "Reports of Committees; the Whitford Committee Report on Copyright and Designs Law." Modern Law Review 40: 685 - 700

Feather, J. 1994. Publishing, Piracy and Politics; An Historical Study of Copyright in Britain. London: Mansell Publishing

Garzone, G. 2010. "Actors, Identities and Roles in Professional and Academic Discourse: An Introduction." in Garzone, G. and Archibald, J. (eds) Discourse, Identities and Roles in Specialized Communication. Switzerland: Peter Lang

Geiger, C. 2010. "The Future of Copyright in Europe: Striking a Fair Balance Between Protection and Access to Information." Intellectual Property Quarterly 1:1 - 14

Gove, M. 2014. The Purpose Of Our School Reforms, Delivered on 7 June 2014 at Policy Exchange, available at: https://www.gov.uk/government/speeches/the-purpose-of-ourschool-reforms 
Groves, P. 1991. Copyright and Designs Law: A Question of Balance. London: Graham and Trotman Ltd

Hargreaves, I. 2011. Digital Opportunity; A Review of Intellectual Property and Growth. London: Intellectual Property Office

Henshel, R. 1978. "Considerations on the Deterrence and System Capacity Models." Criminology (35)16: 40

Hess, G. F. and Friedland, S. 1999. Techniques for Teaching Law. North Carolina: Carolina Academic Press

HL Debate 12 November 1987. Hansard. Copyright, Designs and Patents Bill. Vol 489 cc1476-540. The Secretary of State for Trade and Industry Lord Young of Graffham: 1476

HL Debate 28 April 1988, Hansard. Copyright, Designs and Patents Bill. Vol 132 cc525-99. Mr. Kenneth Clarke: 252

Hooper, R. and Lynch, R. 2012. Copyright Works Streamlining Copyright Licensing for the Digital Age An Independent Report. London: Intellectual Property Office

Johnstone, R. 1996. Printed Teaching Materials: A New Approach for Law Teachers. London: Cavendish Publishing

Kantar Media. 2015. Online Copyright Infringement Tracker Wave 5 (Covering period March - May 2015) Overview and Key Findings. London: Intellectual Property Office. available at: https://www.gov.uk/government/uploads/system/uploads/attachment_data/file/449592/new OCl_doc_290715.pdf

Kariyawasam, R. and Low, H. Y. 2014. "Teaching Business Law to Non-Law Students." Journal of University Teaching and Learning Practice 11(2): Article 9

Lee, Y. H. 2015. "United Kingdom Copyright Decisions and Legislative Developments 2014." ICC 46(2): 226-237

Leopold, P. M. 1977. "Reports Of Committees: The Whitford Committee Report on Copyright and Designs Law." The Modern Law Review 40(6): 685 - 705

Lester, D. and Mitchell, P. 1989. Joynson-Hicks on UK Copyright Law. London: Sweet and Maxwell

Litman, J. 2006. Digital Copyright. New York: Prometheus Books

Lustbader, P. 1999. "Seven Principles for Good Practice in Legal Education: Principle 7:

Good Practice Respects Diverse Talents and Ways of Learning." Journal of Legal Education 49: $448-458$

McAuliffe, K. 2013. "The Limitations of a Multilingual Legal System." International Journal for the Semiotics of Law 26 (4): 861-882

McAuliffe, K. 2014. "Translating Ambiguity." Journal of Comparative Law 9(2): 65-87

Merkin, R., 1989. Richards Butler on Copyright, Designs and Patents: The New Law. London: Longman 
Muller, E. L. 1995. "A New Law Teacher's Guide to Choosing a Casebook." Journal of Legal Education 45: 557 - 567

Neville Brown L. 1988. "British and French Statutory Drafting: A Review Article." I.C.L.Q 37(3): 696-701

Owens, A. and Wex, I. 2010. "What are the Challenges Involved and the Strategies Employed in Teaching Australian Law to Non-Law Students from Non-English Speaking Backgrounds." Journal of the Australasian Law Teachers Association 89(1): 89 - 98

Palfrey, J. Gasser, U. Simun, M. and Barns, R. F. 2009. "Youth, Creativity and Copyright in the Digital Age." International Journal of Learning and Media 1(2): 79 - 97

Rumelhart, D. E. and Norman, D. A. 1981. "Analogical Processes in Learning" in Anderson, J. R. (ed) Cognitive Skills and Their Acquisition. Hillsdale, NJ: Lawrence Erlbaum Associates Inc

Rundus, D. and Atkinson, R. C. 1970. "Rehearsal Processes in Free Recall, a Procedure for Direct Observation." Journal of Verbal Learning and Verbal Behaviour 9: 99 -105

Schwartz, M. H. 2011. "Improving Legal Education By Improving Casebooks: Fourteen Things Casebooks Can Do To Produce Better And More Learning." Elon Law Review 27 (3): $27-63$

Schwartz, M. H. 2001. "Teaching Law by Design: How Learning Theory and Instructional Design Can Inform and Reform Law Teaching." San Diego Law Review 38: 347 - 375

Sterling, J.A. L. and Mendis D. 2015. "Regional Conventions, Treaties and Agreements: Summary" in Cook, T. (ed) Sterling on World Copyright Law. London: Sweet \& Maxwell

Government Response. 2014. Technical Review of Draft Legislation on Copyright Exceptions: available at:

https://www.gov.uk/government/uploads/system/uploads/attachment_data/file/308732/respo nse-copyright-techreview.pdf

The Gregory Committee. 1952. The Board of Trade Report of the Copyright Committee. Cmnd. 8662. Preliminary to the Report. London: Her Majesty's Stationary Office

The Whitford Committee 1977. Copyright and Designs Law, Report of the Committee to Consider the Law on Copyright and Designs. Cmnd 6732. London: Her Majesty's Stationary Office

Tulving, E. 1972. "Episodic and Semantic Memory" in Tulving, E. and Donaldson, W. (eds) Organisation of Memory. Hillsdale NJ: Lawrence Erlbaum Associates Inc

Viscount Younger of Leckie. 2014. New Exceptions to Copyright Reflect Digital Age, Press Release, June 2014, Available at: https://www.gov.uk/government/news/new-exceptions-tocopyright-reflect-digital-age

Wanger, A. and Cacciaguidi-Fahy, S. 2006. Legal Language and the Search for Clarity. Germany: Peter Lang

Watson, S. Zizzo, D. and Fleming, P. 2014. Determinants and Welfare Implications of Unlawful File Sharing: A Scoping Review. CREATe Working Paper 2014/05 
Weatherley, M. 2014. Copyright Education and Awareness - A Discussion Document.

Available at http://www.cubismlaw.com/wp-content/uploads/2015/06/mweatherly-copyrighteducation-awareness.pdf

Weist, R. M. 1972. "The Role of Rehearsal: Recopy or Reconstruct?" Journal of Verbal Learning and Verbal Behaviour 11: 440-445

Williams, C. 2006. "Fuzziness in Legal English: What Shall We Do with 'Shall”' in Wanger, A. and Cacciaguidi-Fahy, S. (eds) Legal Language and the Search for Clarity. Germany: Peter Lang

Willingham, D. T. 2007. "Critical Thinking, Why Is It So Hard to Teach?" American Educator: $8-19$

Willingham, D. T. 2008. "What Will Improve a Student's Memory?" American Educator. 17 44

Xanthaki, H. 2014. Drafting Legislation: Art and Technology of Rules for Regulation. Oxford: Hart Publishing

Zander, M. 2004. The Law Making Process. Cambridge: Cambridge University Press 